\author{
International Journal of Translational \\ Medical Research and Public Health (20I7), Volume I, Issue I, I4-2 I
}

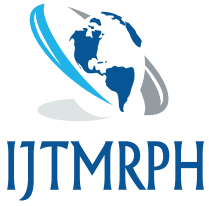

INTERNATIONAL JOURNAL OF TRANSLATIONAL Medical Research and Public Health ISSN: 2576-9499 (Online)

ISSN: 2576-9502 (Print)

Available online at www.ijtmrph.org

DOI: 10.21 106/ijtmrph.27

\title{
ORIGINALARTICLE | ADOLESCENT REPRODUCTIVE HEALTH Sociodemographic Determinants of Early, Normal, and Delayed Menarche among Female College-Aged Students in Bangladesh
}

\author{
Mst. Selina Khatun, MSc'; Md. Rafiqul Islam, $\mathrm{PhD}^{\prime}$; Md. Nazrul Islam Mondal, $\mathrm{PhD}^{1 \otimes}$; \\ Md. Nazrul Hoque, $\mathrm{PhD}^{2}$; Clyde McNeil, MBA²; Fatema Siddiqua, MBBS, FCPS ${ }^{3}$ \\ 'Department of Population Science and Human Resource Development, University of Rajshahi, Rajshahi 6205, Bangladesh; ${ }^{2} \mathrm{Hobby}$ Center for Public \\ Policy, University of Houston, 306 McElhinney Hall, Houston, TX 77204-502I, USA; ${ }^{3}$ Department of Gynecology and Obstetrics, Islami Bank Medical \\ College and Hospital, Rajshahi 6203, Bangladesh \\ Corresponding author email: nazrulupm@gmail.com
}

\section{ABSTRACT}

Introduction: The onset of menstruation in adolescence is an important part of the maturational process. However, little is known about the determinants of menarche and menstrual disorders among university students in Bangladesh. The aim of this study was to identify the factors that influence the menarcheal age of adult female students in Rajshahi University, Bangladesh.

Methods: The data were collected from I,000 female students at Rajshahi University using a purposive sampling technique with direct interview method. The cross-sectional data were used for univariate analysis, to describe each variable and its attributes; and bivariate analysis, to find the associations among the variables.

Results: The results revealed that among the respondents more than half (54\%) experienced menarche at an early age, more than one-third (37.8\%) experienced menarche at normal age, and a few (8.2\%) experienced menarche at a later age. The results also revealed that a few (9.2\%) respondents experienced irregular menstrual cycles and, most of the respondents $(69.2 \%)$ suffered menstrual pain. The menarcheal age was significantly associated with their place of residence. The association between age at menarche and socioeconomic factors was found to be statistically significant. The students having lower mean age at menarche tend to live in urban areas with high family income rather than rural areas with middle or low family income.

Conclusion and Implications for Translation: Most of the respondents experienced early menarche and suffered from menstrual pain. Sociodemographic factors were found significantly associated with age at menarche. Information on the factors that influence the menarcheal age of adult female students and related issues on reproductive health need special attention.

Keywords:Age at Menarche - Sociodemographic Factors - Duration of Menstrual Flow • Menstrual Cycle

Copyright @ 2017 Khatun et al. Published by Global Health and Education Projects, Inc. This is an open-access article distributed under the terms of the Creative Commons Attribution License CC BY 4.0. 


\section{Introduction}

Menarche is the first menstrual period and the most important event among the various pubertal changes in girls, and it is the first indicator of reproductive capacity in women.' The most important dimension in the whole process of female puberty is the onset of menstruation. ${ }^{2}$ The commencement of menstruation in adolescents is an important developmental milestone and it is the evidence of fully developed reproductive ability. ${ }^{3}$ The menarcheal ages are classified as early ( $<12$ years), normal/ideal ( $12-14$ years) and delay/ late $\left(>14\right.$ years).$^{4}$ The severity of childhood physical or sexual abuse is associated with both early and late-onset of menarche. ${ }^{5}$ The age at menarche is a predictor of several complications related to pregnancy and diseases in women's future lives. ${ }^{6}$ For example, early onset of menarche is a high-risk factor for breast cancer and heart disease, whereas delayed menarche adversely affects reproductive function. In addition, early menarche is the main cause of high fertility and higher fertility rates (adolescent fertility and total fertility), increased mortality, and decreased life expectancy. ${ }^{7-11}$ The menarcheal age is associated with cardiovascular disease (CVD), diabetes, etc. ${ }^{22}$

Menstruation is a normal physiological process that begins during adolescence and may be associated with various symptoms occurring before or during the menstrual flow. ${ }^{13}$ Menstrual disorders include premenstrual symptoms, diarrhea, prolonged menstrual bleeding, and emotional disturbances. ${ }^{3}$ Irregular menstrual cycles have considerable effects on women's health. ${ }^{14}$ Before or during their menstrual period, some females experience abdominal pain which usually begins one or two days before the menstrual flow and may continue through the first two days of menstruation. ${ }^{15}$

A good number of research studies on age at menarche have already been conducted in different areas globally. Among them most related to this study are explained here. According to one literature review, menarche is influenced by genetics, socioeconomic and environmental factors. ${ }^{16}$ A study of Chinese participants found that menarcheal age was associated with future risk of diabetes. ${ }^{17}$ Socioeconomic and demographic factors were identified as important predictors of age at menarche in a study of Polish women. ${ }^{18}$ The socioeconomic factors were identified related to various symptoms occurring before or during menstruation. ${ }^{13}$ According to a prior study, while childhood obesity is increasing and socioeconomic studies changing, the recent data on average age of menarche is largely unknown. ${ }^{19}$ Researchers have studied menstruation among Bangladeshi females, and tried to find out the relationships between age at menarche and post-menarcheal growth, marriage, anthropometric measures and sociodemographic factors. ${ }^{20-24}$ More importantly, researchers have shown that the mean age at menarche has declined in developed as well as developing countries. ${ }^{25-31}$ However, no sound study has concentrated on Bangladesh to determine the sociodemographic factors that most influence age at menarche. Therefore, the main aim of this study was to examine the sociodemographic factors that influence menstrual characteristics (especially age at menarche) of adult female students in Rajshahi University, Bangladesh.

\section{Methods}

The sample size consisted of I,000 female students aged 19-28 years residing in the female student halls at the University of Rajshahi, Bangladesh.The university has five female halls of residence in which a total of 3,500 students are available at any time. The study was based on primary data collected from April I, 2012 to April 30,20I2.The sample was selected using a purposive sampling technique and direct interview method using a standard questionnaire. Both univariate and bivariate analyses were used to analyze the data. Mean, standard deviation (SD), and simple percentage were determined. The Chisquare test was used for the significance level and $p<0.05$ was considered statistically significant. To examine the influences of sociodemographic factors on menstrual characteristics, residence and monthly family income were considered as dependent variables. The predictors were age at menarche, duration of menstrual flow, menstrual cycle length, regularity of menstrual cycle, premenstrual symptoms, menstrual pain, menstrual fever, and class absenteeism. Statistical Package for Social Sciences version 18.0 (SPSS Inc., Chicago, IL, USA) was used for statistical analysis. 


\section{Results}

The percentage distributions on menstrual characteristics of adult female students at Rajshahi University in Bangladesh are presented in Table I. The results revealed that most of the respondents (54\%) were found in the early menarcheal age, more than one-third respondents (37.8\%) were found in

Table I: Percentage distributions on menstrual and selected characteristics of university students $(\mathrm{N}=\mathrm{I}, 000)$

\begin{tabular}{lc}
\hline Menstrual characteristics & Number (\%) \\
\hline Age at menarche (years) & \\
\hline$<$ I2 (Early) & $540(54.0)$ \\
\hline I2-I4 (Normal) & $378(37.8)$ \\
\hline$>$ I4 (Late) & $82(8.2)$ \\
\hline Duration of menstrual flow (days) & \\
\hline$\leq 6$ & $843(84.3)$ \\
\hline$>6$ & $157(15.7)$ \\
\hline Menstrual cycle length (days) & \\
\hline$\leq 32$ & $722(72.2)$ \\
\hline$>32$ & $278(27.8)$ \\
\hline Regularity of menstrual cycle & \\
\hline Regular & $908(90.8)$ \\
\hline Irregular & $92(9.2)$ \\
\hline Premenstrual symptoms & \\
\hline Yes & $605(60.5)$ \\
\hline No & $395(39.5)$ \\
\hline Menstrual pain & \\
\hline Yes & $692(69.2)$ \\
\hline No & $308(30.8)$ \\
\hline Menstrual fever & $178(17.8)$ \\
\hline Yes & $822(82.2)$ \\
\hline No & $458(45.8)$ \\
\hline Class absenteeism & $542(54.2)$ \\
\hline Yes & $440(44.0)$ \\
\hline No & $560(56.0)$ \\
\hline Residence & $408(40.8)$ \\
\hline Urban & $428(42.8)$ \\
\hline Rural & $164.4)$ \\
\hline Monthly family income & \\
\hline High & \\
\hline Middle & \\
\hline Low & \\
\hline
\end{tabular}

the normal menarcheal age, and a few respondents $(8.2 \%)$ were found in the late menarcheal age. In this study, almost all $(84.3 \%)$ respondents have shorter menstrual flow ( $\leq 6$ days), and a few respondents (I5.7\%) have the longer menstrual flow (> 6 days) In the case of menstrual cycle length, most of them (72.2\%) experienced the shorter length ( $\leq 32$ days) and around one-third (27.8\%) of respondents have the longer length (> 32 days). Almost all (90.8\%) experienced the regular menstrual cycle. This study identified that most of respondents experienced premenstrual symptoms (60.5\%) and most suffered menstrual pain (69.2\%), and a few (17.8\%) suffered from menstrual fever. Consequently, around half of them (45.8\%) were found absent from their classes during menstruation.

The percentage distributions of menstrual characteristics by residence of the respondents are presented in Table 2. The largest percentage (27.9\%) of respondents were found in the early age at menarche category. The menarcheal age was found statistically significantly associated with their place of residence. Regularity of their menstrual cycle, was reported more often in the rural areas (5I.I\%) than that of urban areas (39.7\%). We found that $6.8 \%$ of respondents suffered menstrual fever in urban areas, as compared to $11 \%$ in rural locations; this is a statistically significant association. About $29.5 \%$ and $39.7 \%$ of respondents suffered menstrual pain in urban and rural areas respectively.

The percentage distributions on menstrual characteristics of the respondents by their socioeconomic status are presented in Table 3 . The results revealed that the largest percentage of respondents experienced menarcheal at an early age in high income families. For respondents in high income families, $25.3 \%$ experienced early menarcheal age, $13.1 \%$ experienced menarcheal at a normal age, and $2.4 \%$ of respondents experienced late menarcheal age. Similarly, $22.9 \%$ of respondents from middle income families experienced menarcheal at an early age, $16 \%$ experienced at a normal menarcheal age, and $3.9 \%$ experienced menarcheal at a later age. For the respondents who were in low income families $5.8 \%, 8.7 \%$, and $\mathrm{I} \%$ experienced early, normal and late menarcheal ages, respectively. The study identified 
there is a statistically significant difference on age at menarche among the subjects living in high, middle or low family income group. The menstrual cycle was found regular in $36.8 \%$ of high income families, $39.5 \%$ in middle income families, and $14.5 \%$ in low income families' respondents. About 22.7\%, 30.3\% and II.2\% subjects suffered from menstrual pain in high, middle and low family income groups respectively.

The case summaries of age at menarche with socioeconomic status by place of residence are

Table 2: Associations between menstrual characteristics with residence

\begin{tabular}{|c|c|c|c|}
\hline \multirow{2}{*}{$\begin{array}{l}\text { Menstrual } \\
\text { characteristics }\end{array}$} & \multicolumn{2}{|c|}{ Residence (\%) } & \multirow[t]{2}{*}{$p$-values } \\
\hline & Urban & Rural & \\
\hline \multicolumn{4}{|c|}{ Age at menarche (years) } \\
\hline < I2 (Early) & $279(27.9)$ & $261(26.1)$ & 0.000 \\
\hline I2-I4 (Normal) & $131(13.1)$ & $247(24.7)$ & \\
\hline$>14$ (Late) & $30(3)$ & $52(5.2)$ & \\
\hline \multicolumn{4}{|c|}{$\begin{array}{l}\text { Duration of menstrual } \\
\text { flow (days) }\end{array}$} \\
\hline$\leq 6$ & $378(37.8)$ & $465(46.5)$ & 0.124 \\
\hline$>6$ & $62(6.2)$ & $95(9.5)$ & \\
\hline \multicolumn{4}{|l|}{$\begin{array}{l}\text { Menstrual cycle } \\
\text { length (days) }\end{array}$} \\
\hline$\leq 32$ & $318(31.8)$ & $404(40.4)$ & 0.511 \\
\hline$>32$ & $122(12.2)$ & $156(15.6)$ & \\
\hline \multicolumn{4}{|c|}{$\begin{array}{l}\text { Regularity of menstrual } \\
\text { cycle }\end{array}$} \\
\hline Regular & 397 (39.7) & $5 I I(5 I . I)$ & 0.327 \\
\hline Irregular & $43(4.3)$ & $49(4.9)$ & \\
\hline \multicolumn{4}{|c|}{ Premenstrual symptoms } \\
\hline Yes & $265(26.5)$ & $340(34)$ & 0.463 \\
\hline No & $175(17.5)$ & $220(22)$ & \\
\hline \multicolumn{4}{|l|}{ Menstrual pain } \\
\hline Yes & $295(29.5)$ & $397(39.7)$ & 0.108 \\
\hline No & $145(14.5)$ & $163(16.3)$ & \\
\hline \multicolumn{4}{|l|}{ Menstrual fever } \\
\hline Yes & $68(6.8)$ & $110(\mathrm{II})$ & 0.050 \\
\hline No & $372(37.2)$ & $450(45)$ & \\
\hline \multicolumn{4}{|l|}{ Class absenteeism } \\
\hline Yes & $202(20.2)$ & $256(25.6)$ & 0.501 \\
\hline No & $238(23.8)$ & $304(30.4)$ & \\
\hline Total & $440(44.0)$ & $560(56.0)$ & \\
\hline
\end{tabular}

presented in Table 4. The results revealed that respondents have lower mean of menarcheal age if they come from a high income family.

The mean, SD, median, and modal results of age at menarche are presented in Table 5 . The results identified that there was a statistical significant difference of mean age at menarche according to high, middle, and low income families' respondents. Median

Table 3: Associations between menstrual characteristics and monthly family income

\begin{tabular}{lll}
\hline Menstrual & \multicolumn{2}{c}{ Monthly family income (\%) } \\
\cline { 2 - 3 } characteristics & High Middle Low \\
\hline
\end{tabular}

Age at menarche

(years)

\begin{tabular}{lcccc}
$<$ I2 (Early) & $253(25.3)$ & $229(22.9)$ & $58(5.8)$ & 0.000 \\
\hline I2-I4 (Normal) & I3I (I3.I) & $160(16)$ & $87(8.7)$ & \\
$>$ I4 (Late) & $24(2.4)$ & $39(3.9)$ & $10(1)$ &
\end{tabular}

Duration of menstrual flow

(days)

\begin{tabular}{ccccc}
\hline$\leq 6$ & $353(35.3)$ & $348(34.8)$ & $142(14.2)$ & 0.080 \\
\hline$>6$ & $55(5.5)$ & $80(8)$ & $22(2.2)$ & \\
\hline
\end{tabular}

Menstrual cycle

length (days)

\begin{tabular}{lcccc}
\hline$\leq 32$ & $302(30.2)$ & $297(29.7)$ & $123(12.3)$ & 0.224 \\
\hline$>32$ & $106(10.6)$ & $131(13.1)$ & $4 I(4.1)$ & \\
\hline $\begin{array}{l}\text { Regularity of } \\
\text { menstrual cycle }\end{array}$ & & & & \\
\hline Regular & $368(36.8)$ & $395(39.5)$ & $145(14.5)$ & 0.296 \\
\hline Irregular & $40(4)$ & $33(3.3)$ & $19(1.9)$ & \\
\hline
\end{tabular}

Premenstrual

symptoms

\begin{tabular}{lcccc}
\hline Yes & $239(23.9)$ & $268(26.8)$ & $98(9.8)$ & 0.479 \\
\hline No & $169(16.9)$ & $160(16)$ & $66(6.6)$ & \\
\hline Menstrual pain & & & & \\
\hline Yes & $277(27.7)$ & $303(30.3)$ & $1112(11.2)$ & 0.637 \\
\hline No & $131(13.1)$ & $125(12.5)$ & $52(5.2)$ & \\
\hline Menstrual fever & & & & \\
\hline Yes & $64(6.4)$ & $78(7.8)$ & $36(3.6)$ & 0.199 \\
\hline No & $344(34.4)$ & $350(35)$ & $128(12.8)$ & \\
\hline $\begin{array}{l}\text { Class } \\
\text { absenteeism }\end{array}$ & & & & \\
\hline Yes & $174(17.4)$ & $204(20.4)$ & $80(8)$ & 0.244 \\
\hline No & $234(23.4)$ & $224(22.4)$ & $84(8.4)$ & \\
\hline Total & $408(40.8)$ & $428(42.8)$ & $164(16.4)$ & \\
\hline
\end{tabular}


age at menarche was found to be 12 years in both high, and middle income family respondents and it was 13 years for low family respondents. Furthermore, there is statistical difference on mean age at menarche among the subjects living in urban and rural residence. Median age at menarche was found 12 years in urban area and 13 years of rural area respondents.

The Stem-and-Leaf plot of age at menarche by place of residence is presented in Figure I.The mean age at menarche of the respondents is above the middle point of the plot for those respondents who live in rural areas, whereas the mean age at menarche is nearly at the middle point for those respondents who live in urban areas. The later age at menarche was found more among the respondents who came from rural areas than that of the respondents who were in the urban areas.

Figure 2 shows the Stem-and-Leaf plot of age at menarche for monthly family income. It shows that

Table 4: Mean age at menarche with socioeconomic status by place of residence

\begin{tabular}{|c|c|c|c|}
\hline \multirow[t]{2}{*}{$\begin{array}{l}\text { Socioeconomic } \\
\text { status }\end{array}$} & \multicolumn{3}{|c|}{$\begin{array}{c}\text { Family Income } \\
\text { (Mean } \pm S D)\end{array}$} \\
\hline & $\begin{array}{c}\text { High } \\
\text { family }(\mathbf{N})\end{array}$ & $\begin{array}{c}\text { Middle } \\
\text { family (N) }\end{array}$ & $\begin{array}{c}\text { Low } \\
\text { family }(N)\end{array}$ \\
\hline \multicolumn{4}{|l|}{ Residence } \\
\hline $\begin{array}{l}\text { Urban } \\
\pm S D\end{array}$ & $\begin{array}{c}|I .8| \\
(253) \pm I .78\end{array}$ & $\begin{array}{c}11.91 \\
(162) \pm 1.74\end{array}$ & $\begin{array}{c}12.88 \\
(25) \pm 1.13\end{array}$ \\
\hline $\begin{array}{l}\text { Rural } \\
\pm S D\end{array}$ & $\begin{array}{c}12.12 \\
(151) \pm 1.66\end{array}$ & $\begin{array}{c}12.52 \\
(270) \pm 1.60\end{array}$ & $\begin{array}{c}12.79 \\
(139) \pm 1.65\end{array}$ \\
\hline
\end{tabular}

SD: Standard Deviation for the respondents who belong to the high and low income families, their mean age at menarche was found nearly in the middle point of the plot. In contrast, the mean age at menarche was for those below the middle point of those respondents who belong to the middle income families. It is clear that the respondents' age at menarche was found earlier who belong to the middle income families compared to the respondents who live in the low income families.

\section{Discussion}

Though menstruation is a normal physiological process, it is related to premenstrual and menstrual disturbances. These disturbances may sometimes be very severe leading to loss of working days. These two socioeconomic factors: place of residence and monthly family income, are determinative of what age a person will experience menarcheal. A woman's age at menarche may be related to later reproductive performance, including age at first birth and risk of spontaneous abortion. But, menstruation and menstrual practices are still clouded by taboos and socio-cultural restrictions resulting in adolescent girls remaining ignorant of the scientific facts and hygienic health practices, which sometimes result into adverse health outcomes. ${ }^{32-34}$ The results of this study revealed that around one-in-ten (9.2\%) of the respondents reported that their menstrual cycles were irregular. Our study identified that most of the respondents (60.5\%) experienced premenstrual symptoms. About $45.8 \%$ of the respondents were unable to attend their classes that affect their daily learning or other activities (data not shown). Abdominal pain and premenstrual symptoms were perceived as the most distressing

Table 5: Mean, SD, median and modal value of age at menarche by socioeconomic factors

\begin{tabular}{|c|c|c|c|c|c|c|}
\hline \multirow[t]{2}{*}{ Variables } & \multicolumn{4}{|c|}{ Age at menarche (years) } & \multicolumn{2}{|c|}{$95 \% \mathrm{Cl}$} \\
\hline & Mean \pm SD & Median & Minimum & Maximum & Lower & Upper \\
\hline \multicolumn{7}{|c|}{ Monthly family income } \\
\hline High & $11.93 \pm 1.74$ & 12.00 & 9.00 & 16.00 & 11.76 & 12.10 \\
\hline Middle & $12.29 \pm 1.68$ & 12.00 & 9.00 & 16.00 & 12.13 & 12.45 \\
\hline Low & $12.80 \pm 1.58$ & 13.00 & 9.00 & 16.00 & 12.56 & 13.05 \\
\hline \multicolumn{7}{|l|}{ Residence } \\
\hline Urban & $11.90 \pm 1.75$ & 12.00 & 9.00 & 16.00 & 11.74 & 12.07 \\
\hline Rural & $12.48 \pm 1.65$ & 13.00 & 9.00 & 16.00 & 12.34 & 12.62 \\
\hline
\end{tabular}

SD: Standard Deviation, Cl: Confidence Interval 


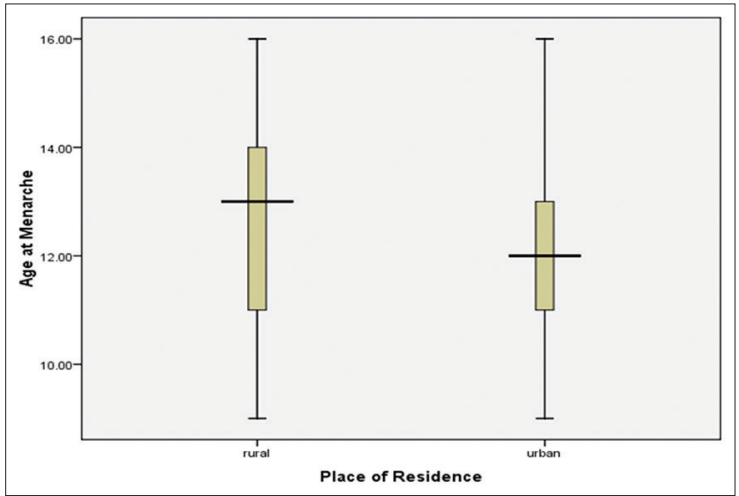

Figure I: Stem-and-Leaf plot of age at menarche by place of residence

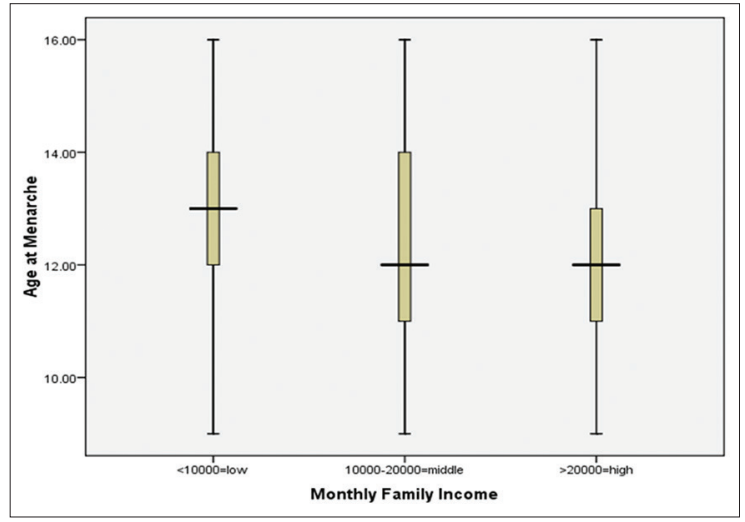

Figure 2: Stem-and-Leaf plot of age at menarche for monthly family income

problems leading to class absenteeism for the university students. Dysmenorrhea and premenstrual symptoms have been reported to be one of the most frequent causes of absenteeism from school and work. ${ }^{13}$

The study also found that the subjects living in urban areas had a younger (II.9 years) mean age at menarche as compared to 12.48 years of age for those residing in rural areas. This result is consistent with a 2005 study conducted in Nigeria. ${ }^{35}$ Moreover, the respondents who live in high-income families reported a younger mean age at menarche (II.93 years) as compared with 12.29 years and 12.8 years for middle- and low-income family respondents, respectively. This is consistent with the findings of the study conducted for the Swiss population. ${ }^{31}$ The respondents from high socioeconomic classes and urban areas have lower mean age of menarche as compared to the respondents in the middle- and lowsocioeconomic classes in both urban and rural areas, which is consistent with a study conducted in India. ${ }^{13}$

The difference of menarcheal ages clearly is a reflection of the discrepancy between social class and earning power in Bangladesh today. Most financially solvent persons are placed within the middle class because of their educational attainment. They are generally richer and have more assets and therefore a better standard of living than persons who are classified as the high social class. This is reflected in the mean menarcheal age of their daughters. They are better nourished and therefore have a better physiologic condition. This may also contribute to the generally lower mean menarcheal age of girls in urban area.

\section{Conclusions and Implications for Translation}

The study identified that around half of the female university students have early menarcheal age. Urban area and high family status students' have lower mean age at menarche than that of rural areas, or middle and low family status students. Stated differently, more students in rural areas experience menarche at a later age when compared to the students living in urban areas. Thus, the study concluded that, sociodemographic factors have significant effects on age at menarche of the female university students in Bangladesh. The government should decide the appropriate age that children should be introduced to the subject of menarche; sex education; contraception, sanitary practices, and choosing the appropriate age for first marriage. Adolescents and parents must increase their awareness of the potential impact of menarche at an early age. The government should design and implement the various health programs related to reproductive healthcare of women in their appropriate ages because early age menarche is one of the factors for health complications. More research is needed in this area.

\section{Compliance with Ethical Standards}

Conflict of Interest: The authors declare no relevant conflict of interest. Financial Disclosure: Nothing to 
declare. Funding/Support: There was no funding for this study. Ethics Approval: Ethics approval was not required for this study. Acknowledgment: The authors gratefully acknowledge the Department of Population Science and Human Resource Development, Faculty of Science, University of Rajshahi; Bangladesh where the study has been conducted.Thanks also to the editor and referees for their valuable comments and criticisms, which lead to greatly improved version of this paper. Disclaimer: None.

\section{Key Messages}

Female college students in Bangladesh report early onset of menarche and this age varies across various sociodemographic characteristics.

Female students living in urban areas and those from high-income families report lower mean age at menarche compared to their counterparts from rural areas and poor families.

- Increased awareness of the potential impact of menarche on academic and other activities is recommended for parents and when age-appropriate for adolescents.

\section{References}

I. Sloboda DM, Hart R, Doherty DA, Pennell CE, Hickey M. Age at menarche influences the prenatal and postnatal growth. J Clin Endocrinol Metab. 2007;92(I):46-50. doi: 10.1210/jc.2006-1378

2. Rigon F, Sanctis VD, Bernasconi S, et al. Menstrual pattern and menstrual disorders among adolescents: an update of the Italian data. Ital J Pediatr. 2012;38:38. doi: 10.1 186/1824-7288-38-38

3. Nwankwo TO, Aniebue UU, Aniebue PN. Menstrual disorder adolescents school girls in Enugu, Nigeria. J Pediatr Adolesc Gynecol. 2010;23(6):358-363. doi: 10.1016/j.jpag.2010.04.001

4. Rokade S, Mane A. A study of age at menarche, the secular trend and factors associated with it. Internet J Biol Anthropol. 2009;(3): 1939-1945.

5. Boynton-Jarrett R, Wright RJ, Putnam FW, Hiber EL, Michels KB. Childhood abuse and age at menarche. J Adolesc Health. 2013;52(2):241-7. doi: 10.1016/j. jadohealth.20I2.06.006

6. Kirkeby MJ, Biering K, Olsen J, Juhl M, Nohr EA. Age at menarche and pregnancy-related pelvic pain. J Obstet Gynaecol Res. 2013;39(5);1037-1044. doi:

\section{|0.1 I I I/jog. I 2008}

7. Akther A, Islam R. A study on age at menarche of school going girls in Bangladesh. Amer J Med Med Sci. 20I2;2(2):4-9. doi: I0.5923/J.AJMMS.20I 20202.02

8. Mondal MNI, Ullah MMMN, Islam MR, Rahman MS, Khan $M N$, et al. Sociodemographic and health determinants of inequalities in life expectancy in least developed countries. Int J MCH AIDS. 20I5;4(I):5766. doi: https://doi.org// 0.21 I06/ijma.43

9. Mondal MNI, Shitan M. Relative importance of demographic, socioeconomic and health on life expectancy in the low- and lower- middle-income countries. J Epidemiol. 20|4;24(2):II7-I24. doi: 10.2188/jea.je20130059

10. Mondal MNI, Shitan M. Impact of socio-health factors on life expectancy in the low and lower middle income countries. Iran J Public Health. 20|3;42(I2):1354-62.

II. Mondal MNI, Shitan M. Factors affecting the HIVIAIDS epidemic: an ecological analysis of global data. Afr Health Sci. 20 I3; I3(2):30 I- I0. doi: I0.43 I4/ahs.vI3i2. I5

12. Qiu C, Chen H, Wen J, et al. Associations between age at menarche and menopause with cardiovascular disease, diabetes, and osteoporosis in Chinese women.J Clin Endocrinol Metab. 2013;98(4):16I2-2I. doi: I0.1210/jc.2012-2919

13. Dambhare DG,Wagh SV, Dudhe JY. Age at menarche and menstrual cycle pattern among school adolescent girls in Central India. Glob J Health Sci. 20 I2;4(I): I05-I I I doi: I0.5539/gjhs.v4n I I 05

14. Hosokawa M, Imazeki S, Mizunuma H, Kubota T, Hayashi $\mathrm{K}$. Investigated the secular trends in age at menarche and time to establish regular menstrual cycling in Japanese women born between 1930 and 1985. BMC Womens Health. 20 I2: 19. doi: I0.I I86/I472-6874-I2-I9

15. Agarwal A, Venkat A. Questionnaire study on menstrual disorders in adolescent girls in Singapore. J Pediatr Adolesc Gynecol. 2009;22(6):365-37I. doi: 10.1016/j.jpag.2009.02.005

16. Karapanou O, Papadimitriou A. Determinants of menarche. Reprod Biol Endocrinol. 2010;8:115. doi: I0.1 I86/I477-7827-8-II5

17. Conway $B N$, Shu $X O$, Zhang $X$, et al. Age at menarche, the leg length to sitting height ratio, and risk of diabetes in middle-aged and elderly Chinese men and women. PLoS One. 20I2;7(3):e30625. doi: I0.137|/journal.pone.0030625 
18. Wronka I, Pawlińska-Chmara R. Menarcheal age and socio-economic factors in Poland. Ann Hum Biol. 2005;32(5):630-8. doi: 10.1080/030 | 4460500204478

19. Al-Awadhi N,Al-Kandari N,Al-Hasan T,Almurjan D,Ali S, Al-Taiar A. Age at menarche and its relationship to body mass index among adolescent girls in Kuwait. BMC Public Health. 20 I 3; I3:29. doi: I 0. I I86/ I47 I-2458- I3-29

20. Ogata A. Age at menarche and marriage in Bangladeshi women. J Trop Med Hyg. 1979;82(4):6874.

21. Haq MN. Age at menarche and the related issue: a pilot study on urban school girls. J Youth Adolesc. 1984;13(6):559-67. doi: 10.1007/BF02088599

22. Riley AP, Huffman SL, Chowdhury AK. Age at menarche and post menarcheal growth in rural Bangladeshi females. Ann Hum Biol. 1989; 16(4):34759. doi: | 0. I080/030|4468900000472

23. Hossain MG, Islam S, Saw A, Zaman TK, Lestrel PE. Age at menarche of university students in Bangladesh: secular trends and association with adult anthropometric measures and socio-demographic factors.J Biosoc Sci. 20 I 0;42(5):677-687. doi: I0. I 0 I7/ S0021932010000210

24. Hossain MG, Khatun MS, Islam MR, et al. Factors associated with age at menarche of secondary school girls in Rajshahi City, Bangladesh. Adv Life Sci. 20I4; 4(2):88-93.

25. Al-Sahab B, Ardern C, Hamadeh M, Tamim H. Age at menarche in Canada: results from the National Longitudinal Survey of Children \& Youth. BMC Public Health. 20I0; 10:736. doi: I0. I I86/I47I-2458-I0-736

26. Al-Sahab B, Ardern C, Hamadeh M, Tamim H. Age at menarche and current substance use among Canadian adolescent girls: results of a crosssectional study. BMC Public Health. 2012; 12: 195. doi: I0.1 I86/ |47|-2458-12-195
27. Anderson S, Must A. Interpreting the continued decline in the average age at menarche: results from two nationally representative surveys of U.S. girls studied I0 years apart.J Pediatr. 2005; I 47(6):753-760.

28. Biro F, Greenspan L, Galvez M. Puberty in girls of the $21^{\text {st }}$ century.J Pediatr Adolesc Gynecol. 20I 2;25(5):289294. doi: 10.1016/j.jpag.2012.05.009

29. DiVall S. The influence of endocrine disruptors on growth and development of children. Curr Opin Endocrinol Diabetes Obes. 2013;20(I):50-55. doi: 10.1097/MED.0b0 I 3e32835b7ee6

30. Demerath EW, Towne B, Chumlea WC, et al. Recent decline in age at menarche: the Fels Longitudinal Study. Am J Hum Biol. 2004;16(4):453-457. doi: 10.1002/ajhb.20039

31. Lehmann A, Scheffler C. What does the mean menarcheal age mean? An analysis of temporal pattern in variability in a historical Swiss population from the 19th and 20th centuries. Am J Hum Biol. 2016;28(5):705-7I3. doi: 10.1002/ajhb.22854

32. Mondal MNI, Hossain MK,Ali MK.Women's status in Bangladesh: an empirical study.J Inst Bangladesh Stud. 2008;(3I):II7-I26.

33. Hossain MK, Mondal MN, Akter MN. Reproductive health rights of women in the rural areas of Meherpur district in Bangladesh. J Reprod Infertil. 201 I; 12(I):23-32.

34. Mondal MNI, Ullah MMMN, Khan $\mathrm{MN}$, et al. Socioeconomic and demographic disparities in knowledge of reproductive healthcare among female university students in Bangladesh. Int J MCH AIDS. 20I5;4(2):32-39. doi: https://doi.org/I0.21 I06/ijma.6I

35. Ikaraoha Cl, Mbadiwe INC, Igwe CU, et al. Menarcheal age of secondary school girls in urban and rural areas of Rivers State, Nigeria. Online J Health All Sci. 2005;4(2). 